Koninklijke Vereniging voor Nederlandse Muziekgeschiedenis

Joan Albert Ban en de theorie der toonkunst. II

Author(s): J. P. N. Land

Source: Tijdschrift der Vereeniging voor Noord-Nederlands Muziekgeschiedenis, Deel 3, 4de

Stuk (1891), pp. 204-218

Published by: Koninklijke Vereniging voor Nederlandse Muziekgeschiedenis

Stable URL: http://www.jstor.org/stable/947647

Accessed: $21 / \overline{/ 06 / 201411: 07}$

Your use of the JSTOR archive indicates your acceptance of the Terms \& Conditions of Use, available at http://www.jstor.org/page/info/about/policies/terms.jsp

JSTOR is a not-for-profit service that helps scholars, researchers, and students discover, use, and build upon a wide range of content in a trusted digital archive. We use information technology and tools to increase productivity and facilitate new forms of scholarship. For more information about JSTOR, please contact support@jstor.org. 


\section{JOAN ALBERT BAN EN DE THEORIE DER TOONKUNST.}

\section{II. *)}

De zongenaamde wedstrijd van Ban met Boësset is in onze Correspondance etc. de Const Huygerss volledig beschreven; dan de laatste stukken zijn in het Latijn gesteld, en verscheidene lezers, die van die taal geen werk maken, hebben mij van tijd tot tijd gevraagd, daaruit te willen mededeelen, welke houding onze landgenoot tegenover de laatste aanmerkingen der Franschen heeft aangenomen.

Ik onderstel dat wie in de zaak belangstelt, ons boek bij de hand heeft, en zal daarom de beide compositiën op den text Me veux tu voir mourir, van Boësset (pag. LXX) en van Ban (p. LXXVI), niet opnieuw doen afdrukken. Men herinnert zich dat Ban in hoofdzaak aan zijn mededinger verweet, dat deze te werk ging »par hazard et rescontre, sans y aporter les regles et la science requise." Terwij] hijzelf woord voor woord door zijne muziek wilde illustreren volgens vaste regelen omtrent de symbolische beteekenis van elke wending die in een melodie voorkomen kan. - had de ander meer als geoefend kunstenaar de aandoeningen trachten uit de drukken, die bet gedichtje achtereenvolgens bij hem opwekte. Van deze meening was ook de ongenoemde »trésorier général", wiens oordeel over Ban's kritisch opstel den 6 Dec. 1640 door Huygens (pas uit Groningen teruggekomen) in den Haag ontvangen werd. Wat hij Ban voornamelijk verweet, was dat hij de woorden of gezegden te veel afzonderlijk in asnmerking nam, in plaats van op het geheel en de darin heerschende geınoedsbewegingen te letten.

$\mathrm{Nu}$ antwoordt Ban in brief XIV (p. XCIV), die aın Huygens gerigt is, tegelijk op de stukken van Boësset en den trésorier (zie

Vervolg van deel I, pag 95-111. 
straks), die hem door zijn Haagschen vriend waren toegezonden. Het eerste bezitten wij niet, maar Mersenne spreekt ervan (p. XC). Ban wil, als een echte geestverwant van Descartes, dat hier de hartstogten niets hebben in te brengen, en enkel volgens de gezonde rede naar de »muzikale waarheid" moet worden gevraagd. Daarom is het hem te doen geweest; en nu komen die anderen met zinledige of willekeurige beweringen, ja met beschuldigingen van onvriendelijke gezindheid, die Mersenne had moeten weten te voorkomen. Want deze heeft immers de proefneming uitgelokt, en Huygens heeft Ban overgehaald om er deel aan te nemen. Het werk van Boësset heeft Ban niet met minachting bejegend, maar enkel aangetoond, waarom hij het op zijn theoretisch standpunt niet kon goedkeuren; zijne eigene muziek stelt hij niet voor als artistiek onverbeterlijk, maar enkel als rationeel en, volgens zijn begrip van de zaak, zielroerend. Hij hoopt dat Mersenne dat in het vervolg naar billijkheid ter harte nemen, en de verdere discussie met de humaniteit, waarop hij zijnerzijds zich steeds heeft toegelegd, tusschen beide partijen gevoerd worden zal.

De Parijsche musici hebben hem geen van allen goed begrepen. Zij verwijten hem vooreerst dat hij in den aanhef der woorden verontwaardiging ziet, terwijl zij immers de klagt van een minnaar behelzen. Maar is dan nooit een minnaar verontwaardigd, of is dat soms de ware verontwaardiging niet? En Boësset erkent immers zelf, dat indien de zin zoo ware als Ban dien begrijpt, hijzelf (Boësset) verkeerd had gedaan toen hij de toonladder met kleine terts verkoos. De Fransche componist (wiens toewijding en kunstvermogen Ban op hoogen prijs stelt) geeft toe dat de inrigting der toonladders waarover wij beschikken (de kerktonen namelijk) zeer uiteenloopt; hoe kan hij niettemin van oordeel zijn dat, in het algemeen gesproken, elk daarvan even geschikt zou zijn om iedere gemoedsaandoening weer te geven, daar toch elk interval (zoo goed als de groote en kleine terts waarvan Boësset gewaagt) zijn eigenaardigen indruk maakt, en in den eenen of den anderen dier tonen meer op den voorgrond treedt; daarin is juist het hoofdbeginsel der zielroerende muziek gelegen, en zijn tegenstander zal niet ontkennen, dat de bedoelde toonstelsels zijn bedacht teneinde in de keus der intervallen en ca- 
dentiën de noodige orde te brengen. De transpositie echter, waardoor Boësset meent dat alle toonladders gelijk gemaakt kunnen worden, doet inderdaad de kracht der oorspronkelijke stelsels te loor gaan; immers wanneer de toonladder b.v. met $\mathrm{C} \mathrm{D}$ begint, bedraagt het eerste interval een tonus major $[8: 9$ of 2.039 gelijke halve tonen]; transponeert men, en begint met $\mathrm{D} \mathrm{E}$, dan wordt dat interval een tonus minor [9:10 of 1.824]. Slechts bij gelijkzwevende temperatuur, die alle intervallen vervalscht, zou die zwarigheid verdwijnen, doch ten koste van de zuiverheid der muziek. Dat neemt niet weg, dat met behoud van de wiskundig zuivere stemming een voorbijgaande afwijking naar andere toonladders volkomen geoorloofd is, en goed te pas gebragt alle toejuiching verdient. De overige aanmerkingen van den ander zullen den schrijver een spoorslag zijn om zich al ijveriger op de volmaking der kunst toe te leggen.

Wat het opstel van den trésorier général betreft, deze verklaart Ban voor een pedant, die niet anders dan Latijn verstaat. Och of hij dit althans goed magtig ware; doch hij erkent, dat hij in menschelijke zaken en talen, voornamelijk het Fransch, nog steeds te weinig ervaren is, en den beoordeelaar dank weet, hem te herinneren aan het vele dat hij nog moet inhalen. Zoo geheel onbekwaam is hij echter niet, of hij heeft indertijd in Frankrijk zelf zijne opmerkingen gemaakt omtrent de gebruikelijke uitspraak, en weet b. v. dat de $e$ in il passe anders klinkt dan in il est passé. Daarop wil hij intusschen geen gewigt leggen, maar laat den Franschen hun gulden vrijheid [p. XCI: ce que l'on n'observe pas tousjours et partout en françois] en allerhande verborgenheden hunner taal die hem ontgaan, en komt tot de zaak zelve.

Met de accenten die hij op de Fransche woorden zet (p. XLI) heeft hij niet anders bedoeld dan aan te wijzen wat de Franschen zelven (zooals de grammaticus Nicod, 1618) lange lettergrepen plegen te noemen; en wel met het oogmerk om de inboorlingen te doen verstaan, hoe hij gedacht heeft de verzen te moeten uitspreken, waardoor zijne compositie mede verklaarbaar worden moet. Heeft hij zich vergist, dan verzoekt hij hem op dit punt te verbeteren; met dat al is het overal een voordeel, wanneer de alledaagsche uitspraak bij de zang door een naauwkeuriger afgemetene vervangen wordt, 
zooals die toch zeker, bij hen die zeer duidelijk willen spreken, ook in Frankrijk reeds in gebruik zal zijn. Zijn de accenten door hem ten onregte aangenomen, terwijl de Franschen ze in den regel veronachtzamen, dan een van beiden : ò zij voldoen niet aan de hoogere eischen hunner eigene taal, of deze is op zichzelf ongeregeld en in zooverre gebrekkig ingerigt. [Het is aardig, ook hier de oude dwaling te ontmoeten, volgens welke de taal een uitvinding is evenals het Volapük genoemde seinstelsel onzer dagen, die meer of minder beantwoordt aan een doel dat men ermede bereiken wilde, in plaats van een natuurvoortbrengsel, slechts ten deele aan onzen wil onderworpen.]

Mogelijk heeft hij de strekking der eerste woorden anders begrepen dan de dichter-zelf; zoo ja, dan is hem zulk een misvatting te vergeven; zoo neen, dan heeft hij ook volgens Boësset gelijk gehad met de groote terts te verkiezen. De verontschuldiging van dezen door den trésorier gaat niet op; indien een verontwaardigde soms met een daling, en zelfs een stervende met een verheffing van stem spreekt, dan volgt daaruit meteen, dat hij dezeltde vrijheid als zijn mededinger had om het een of het ander te doen, te meer wanneer hij redenen kan aanvoeren. Over de transpositie, waarmede men het verschil der toonladders wil te niet doen, heeft hij hierboven het noodige gezegd; men heeft zich ook in dezen niet aan willekeur maar aan de rede te houden, indien er van weten en onderling overleg sprake zal zijn.

Voorts brengt de schatmeester uit zijn schat deze opmerking te berde, dat wanneer men, zooals Ban wil, de hoofdstem en den bas tegelijk naar het accent der woorden laat rijzen en dalen, de aangename verscheidenheid die uit de tegengestelde beweging ontstaat, wordt prijsgegeven. Dat is waar, doch op een noodzakelijkheid valt niet af te dingen; men moet zich duidelijk uitdrukken voordat men met reden behagen kan. Zegt men dat zoodoende de compositie een moeijelijke taak wordt, dan geldt datzelfde immers overal waar iets schoons zal tot stand komen. En de keuze en schikking van intervallen en lettergrepen, zóo dat men èn leert èn aangenaam bezig houdt èn het gevoel opwekt, wordt beter aan de rede dan aan de verbeelding toevertrouwd. Dat hij hier en daar in den rhythmus [»nombre" p. XCIII] gedwaald zou hebben, ontkent hij, omdat die 
naar verkiezing kan worden behandeld; wat de intervallen aangaat heeft hij zich in zijn vorigen brief' genoegzaim uitgeliten. 'Tegen de harmonie meent men dat hij gezondigd heeft; in de oude muziek, wiarbij het minder op den text din op de zich langzaam ontwikkelende verbinding der stemmen ankwam, was dit een zaak van groot beling; in de hedendangsche, met nume in den franschen ariastijl, wordt rij bijzaak.

En waar men zich, om zekere aandoeningen uit te drukken, niet eens meer aan bepaalde toonladders houden wil, warom zou men zich dailr ian strenge harmoniewetten binden? Hij wil de harmonie geheel in den dienst gesteld zien van het zielroerende gezang; de kracht daarvan en de uitwerking van elk accoord op zichzelf mag niet door onnoodige voorschriften omtrent het volgen van het eene na het andere belemmerd worden. De volmaking der kunst door de nieuwe vindingen van dezen tijd doet vele van de regelen der oudere muziek vervallen.

Dat Ban op de woorden een voor een meer dan op den zamenhang zou gelet hebben, ontkent hij ten stelligste. Het aangehaalde voorbeeld cruelle, waar hij verkeerdelijk op de »cruauté toute pure" [p. XCIII] den nadruk zou gelegd hebben, past niet, omdat toch ook met de liefde wreedheid gemengd kan zijn, en de hoogere mate daurvan door grootere intervallen moet worden uitgebeeld. Wil men hem overtuigen, dan zal men andere redenen moeten aanvoeren. Ain het slot is hem nog verweten dat hij geene harmonische fouten afkeurt. Inderdaad wil hij den ervaren kunstenaar groote vrijheden veroorloven, mits de verbinding der stemmen aan de juiste uitdrukking even dienstbaar worde gemaakt als de bouw der melodie, en zich overigens rigie naar hetgeen zijn gehoor toelaat of verbiedt.

Over het geheele twistgeding wil hij nog dit zeggen: Het is hem nooit te doen geweest om anderen te misprijzen of zichzelven boven iemand te verheffen; dat is altijd nadeelig voor een man van studie; laat dwazen zich moeite geven om ijdelen roem te behalen. Voorts heeft hij Mersenne een vriendendienst willen bewijzen, toen deze meermalen gevraagd had, hem met een voorbeeld te toonen, wat hij met zijne muziektheorie trachtte te bereiken. Met de compositie van dat gedichtje kon hij niet volstaan om duidelijk te maken, waarin 
het eigenaardige dier theorie bestond. Daar het om vocale muziek te doen was, meende hij eerst te moeten verklaren, hoe hij zich voorstelde dat de stembuiging volgens de lessen der natuur behoorde te zijn. Hij paste dat op de fransche taal toe zoo goed hij het op grond van vroegere ondervinding en van de spraakleer van Nicod vermogt, enkel om zijn beginsel duidelijker te verklaren, niet om aan vreemdelingen datgene te leeren wat zij uit hun eigen spraakgebruik (afgezien van algemeene beschouwingen) beter moesten weten. Dit hebben de Franschen niet begrepen, en geven nu allerlei te kennen dat wel de spreektaal, maar niet de uitspraak bij het zingen raakt, over welke zij te weinig schijnen te hebben nagedacht. Hijzelf heeft een grondslag voor de verdere discussie willen geven, waar zij meenden dat hij zich opwierp als wetgever voor hunne landtaal. Hij houdt aan zekere beginselen vast die voor elke taal dezelfde zijn; de toepassing daarvan in het bijzonder verlangt hij juist van diegenen die met de bijzondere gewoonten der taal in quaestie ten volle bekend zijn. Vervolgens heeft hij zijne meening ontrouwd omtrent de kracht der intervallen en accoorden.

De beoordeeling van het zangstuk van Boësset en de verklaring van zijne eigene proeve zijn volstrekt niet geschreven om aan te toonen dat deze laatste hoogere kunstwaarde bezit. Waar men niet dezelfde stelregels volgt, is toch een behoorlijke vergelijking onmogelijk; en bovendien, bij een wedstrijd tusschen personen zou de waarheid meer verduisterd dan in het licht gesteld worden. Wat dus bij wijze van persoonlijk gevoelen, zonder bewijs tegen hem aangevoerd is, wil hij beschouwen als niet geschreven. De Franschen toch (het is hem door hunne eigene landgenooten dikwijls verzekerd) zijn doorgaans te haastig in hun oordeelen, en komen eerst later weder tot de rede terug; dat ligt aan den aard van het volk; en daarom houdt hij zich ter zijner tijd voor een uitnoodiging om het vriendschappelijk overleg te hervatten volgaarne aanbevolen.

Wat hij verlangt is eenvoudig dit, dat de toonkunst, in plaats van naar ieders toevallige meening en smaak, naar vaste en bewijsbare regelen beoefend worde, bij hetwelk, blijkens zijne ondervinding, zoowel het verstand als het gehoor hunne rekening vinden. Deze opvatting wil hij niemand opdringen; verkiezen anderen zich ook 
voortaan aan hunne persoonlijke indrukken te houden, naar zijne redenen niet te luisteren, niet eens de proef te nemen naar betgeen hij voorstelt, zich alle denkbare vrijheden en onregelmatigheden te veroorloven, - het staat hun vrij. Wil men echter met hem onderhandelen, hij zal dat nimmer weigeren, mits alwat men beweert met reden gestaafd wordt. Wie dan de overhand behouden zal, is hem or het even; ja hij laat zich liever overwinnen en onderrigten dan dat hij de meester zou willen blijven, en gunt dengenen van wie hij leert, al moest hij daarvoor zijne vroegere overtuiging prijs geven, allen mogelijken lof. $0 \mathrm{~m}$ alvast gelegenheid tot verdere gedachtenwisseling te geven, stelt hij de vraag: of de Franschen het ervoor houden, dat rijne denkbeelden over muziek ook op andere talen, zooals bet Latijn, niet wel toepasselijk zijn, en dat ook daar de natuurlijke afwisseling van lange en korte lettergrepen door den componist verwaarloosd zou mogen worden?

Een dag later (brief XV, pag. CVIII) zendt Ban aan Huygens de fransche papieren, waarvan hij nu meer dan genoeg heeft, terug. Indien de Franschen in het vervolg niet degelijk met hem redeneren willen, zal hij zich niet verder met hen inlaten (ze verachten, zegt hij), om van de verveling die zij hem bezorgen verlost te rijn.

Terzelfder tijd schrijft hij aan Mersenne (brief XVI). De schrifturen van dezen en de anderen bewijzen dat zij niet vatten wat hij eigenlijk wil. Is de warheid niet het doel dat men zich voorstelt; komt men met vitterijen aan in plaats van met redeneringen, dan kan hij zijn tijd nuttiger besteden dan met op dien voet verder te onderhandelen. Mag in de muziek de uitspraak van fransche woorden naar willekeur gewijzigd worden; heeft de dichter iets anders willen zeggen dan Ban in zijn vers dacht te lezen, en daarom zijn werk verkeerd opgezet; dan had men bem dit eenvoudig kunnen te kennen geven, en Ban zou daarin berust hebben, want niet daarom was het hem te doen, maar om zijne compositieleer. Zijne stelling was, dat de natuurlijke voordragt van textwoorden, - met duur van lettergrepen en klemtoon op sommige daarvan, zooals men die in acht neemt wanneer men ze zonder muziek duidelijk declameert, door de muziek niet verdonkerd maar versterkt en verhoogd moet worden. Hij ontrouwde, hoe dat volgens zijne beredeneerde over- 
tuiging, den aard der intervallen en accoorden in anmerking nemende, te bereiken viel ; zijne anteekeningen op de beide toonwerkjes badden geen ander doel dan dit nog beter te doen inzien. En nu redeneert men niet daartegen, maar is verontwaardigd en doet hem allerhande verwijten. Mersenne, van ouds met hem bevriend, had dit aan de fransche schrijvers moeten beduiden; hem was het niet verborgen, dat Ban er niet aan dacht, een Boêsset te verkleinen of wien ook te kwetsen. Bevalt ulieden, dus vervolgt hij, mijne muziek niet, dan is dat niet anders; hoe weinig de uwe behaagt aan goede kunstenarrs hier te lande, die hun halve leven in Italië, in Rome, en aan de hoven van den Keizer en andere vorsten hebben gesleten, heb ik u tot hiertoe niet gemeld, omdat ik niet met meeningen, maar met redenen te doen wil hebben. Dat gij (Mersenne) mijne denkbeelden niet goed verstaat, is mij mede gebleken uit uwe gebrekkige vertaling van mijn »examen" [p. LXX vv.]; mogelijk daarom zoo gebrekkig, omdat gij minder op de hoogte zijt van de muzikale praktijk; hetgeen meest valt op te maken uit de redenen die gij in uw antwoord aanvoert, hoezeer gij die voorzeker met alle bescheidenheid voordraagt. De afwijkingen in die vertaling hebben er zeker mede toe bijgedragen Boësset zoo verstoord te maken. Hadt gij mij niet door Huygens doen vragen om de stukken aan mej. van Schurmann mede te deelen, ik had dat stellig niet gedaan. Om onzer vriendschap wil heb ik mij tot deze proefneming geleend, en haar ben ik die rondborstige verklaring verschuldigd. Overigens heb ik de hoogste achting voor Boësset, en zou mij innig verheugen indien wij over de kunst op degelijke gronden te zamen konden verhandelen. Uzelven ben $i k$ ten zeerste verpligt, en zal gaarne verder alles doen om te toonen hoezeer ik uwen ijver voor kunst en wetenschap op prijs stel. Gij biedt mij de boeken van Aristides Quintilianus en van Doni aan. Het eerste kan mij, zooals gij te verstaan geeft, wel niet veel baten, dockr is om de oudheid van den schrijver mij niet unverschillig. [Hij schreef volgens zijn jongsten uitgever in de eerste eeuw onzer jaartelling.] Met den ander zal ik mij ernstig bezig moeten houden; ik denk hem in een uitroerigen brief vol muzikale mysteriën te zullen antwoorden. [Gio. Batt. Doni - wij bezitten een lateren druk zijner werken in de bibliotheek der 
Vereeniging, Catal. pag. 126 - wordt door Ambros IV. 156 niet zeer gunstig beoordeeld. Zijne goede opmerkingen, vooral over muzikale declamatie, koopt men duur met door een massa ballast heen te worstelen; eerst voor ons zijn die verhandelingen van hooge waarde wegens de muziekgeschiedenis van dien tijd, hoewel zij volstrekt niet met dat doel zijn opgesteld. Vgl. ook pag. LXI-II en LXVII van ons boek.] Van mijnen kant zal ik u proeven mijner zielroerende zangen en ook de voor mej. van Schurmann bestemde muziek toezenden. Voorts verlangt gij mijn oordeel te vernemen over het werk vall Gouy [Jacques de Gouy, kanunnik van Embrun]. Ik zou mij liever niet daaraan wagen, omdat de Franschen zoo ligt vuur vatten; doch $n u$ ge het mij vraagt, wil ik het niet weigeren, zonder den man, wiens naam ik nu voor het eerst van $\mathfrak{u}$ verneem, te kort te willen doen.

Ik acht het zoo goed als onmogelijk, over iets te oordeelen alleen volgens den indruk dien het maakt; hoe wil iemand beslissen tenzij op grond van redenering? De kunst maakt hare werken in overeenstemming met de goede reden die de wetenschap, de theorie, voorschrijft; waar men zich alles veroorlooft, is er geene kunst meer. Hoort iemand iets nieuws, waarvan anderen verzekeren dat het op bewijsbare beginselen steunt, en maakt zich daarover vrolijk onder voorwendsel van zijne vrijheid te bandhaven, dan bedriegt hij zich zelven. Hoe kan nu Gouy het wagen, te spotten over de uitspraak van vreemde talen, die het ")accent" moet volgen, vooral wanneer hij die talen niet verstaat, of anders, zoo hij ze verstaat, geene redenen te berde brengt? Ik voor mij houd mij aan redenen, uit beginselen afgeleid, en tracht mij daarnaar tot in de kleinste bijzonderheid toe te gedragen. Heeft Gouy geene andere redenen daartegenover te stellen, dan valt er met hem niet te twisten. [Uit deze verklaring meen ik te mogen besluiten, dat de kanunnik Gouy de schrijver van brief XIII (p. XCI) en trésorier général van zijn kapittel te Embrun geweest is; vgl. het argument vóor den Lutvin van Boileau : "Le trésorier remplit la première dignité du chapitre dont il est ici parlé, et il officie avec toutes les marques de l'épiscopat."] Wat nu 's mans werk betreft: ik wil tusschen hem en zijn kunstgenoot Bö̈sset geene vergelijking maken; de com- 
positie van dezen komt mij evenwel voor bevalliger te zijn, terwijl die van Gouy door meerdere kracht van modulatie uitmunt en mij beter voldoet. De muzikale vinding en den stijl laat ik ter beoordeeling van uwe landgenooten. 「Gouy had blijkbaar insgelijks een )air de cour" op de ons bekende woorden Me veux tu voir mourir geleverd, dat mogelijk nog wel ergens te vinden zal zijn.] Doch dit verzeker ik $\mathbf{u}$ ten stelligste, dat zoo gij mijne muzikale stijlproeven door mijne leerlingen naar dien eisch kondt hooren zingen, gij mijne redenen beter zoudt doorgronden en het ten volle met mij eens worden.

In een brief van den 18den derzelfde maand (XVII, p. CXII) schrijft Ban aan Huygens, dat hij kennis heeft genomen van de tweede redactie der beoordeeling van zijn kritisch opstel, waarin de Franschen de uitdrukkingen die hem konden grieven, verzacht hadden. Naar aanleiding van dat stuk komt hij nog eens op drie punten terug.

Vooreerst, wat de sierlijkheid der fransche taal aangaat, die tegenwoordig, naar zij zeggen, meer en meer volmaakit wordt, daarover heeft hij nimmer willen redetwisten; dat zijn bijzaken voor wie zich met de muziekleer bezighouden. Ten tweede heeft men hem tegengeworpen, dat waar zijne begrippen omtrent het rijzen en dalen der tonen in overeenstemming met de woorden toegepast worden, de afwisseling en dus het genot verloren gaat. Hij antwoordt, dat de volmaaktheid en het eigenlijke doel der toonkunst niet in het genot dat zij geeft gelegen is; immers zij is bestemd om zoowel to leeren als te streelen en het gemoed te roeren. Zij leert door middel van juiste declamatie van den text; zij streelt en roert door alle mogelijke middelen. Het zou een kinderachtige toonkunst zijn, waarvan met regt gezegd kon worden hetgeen in den Bijbel staat [Matth. 11:17]: „Wij hebben voor $u$ gespeeld en gij hebt niet gedanst; wij hebben $u$ klaagliederen gezongen en gij hebt niet geweend." Dat geldt niet enkel binnen de grenzen der fransche taal; de beroemste kerkvaders hebben daarop gewezen, vooral met het oog op de gewijde muziek. Wat wil men dezen antwoorden, wanneer zij verklaren dat de voordragt meer die van een lezer dan die van een gewonen zanger behoort te zijn? Waarom behoort dat, anders dan om tevens te leeren en te roeren? Dit laatste wordt door enkele heenenweerbeweging in intervallen niet verkregen; men heeft te letten op de natuurlijke eigenschappen III. 
dier intervallen, zooals de stellige wetenschap ze ons leert kennen. Van waar ontleent men die kennis? Uit de overweging van het verschil der evenredigheden tusschen de toonhoogten, waarop vervolgens de leer der accoorden gebouwd wordt. Zoo komt de harmonie in den ruimeren zin des woords, dat is, de juiste schikking van melodie zoowel als harmonie in de gewone beteekenis, tot stand; van daar dan de aandoening van het gemoed als bereiking van het hoofddoel, en het genot als bijkomende uitwerking.

In de derde plaats meent de fransche schrijver, dat de beteekenis der muziek in de vinding der zangwijze en in de schoonheid van deze en de begeleiding zou gelegen zijn, terwijl de declamatie niet tot hare middelen maar tot die van de kunst des redenaars behoort. Het zou der toonkunst eigen zijn, dat zij alle aandoeningen ter zijde liet en een ideale kalmte bewaarde. Wel verre van dit te beamen, houdt Ban vol, dat het opwekken van aandoeningen veeleer de taak is van den toonkunstenaar dan van den spreker, ja dat de uiterlijke welsprekendheid, met hare velerlei stembuigingen, gelijk al de ouden leeren, zelve uit de muziek ontsprongen is. Een muziek die niet bij magte ware, booze hartstogten te bannen, en geestdrift voor alwat goed is te bevorderen, zou een nuttelooze weelde niet alleen, maar voor het hoogere leven, zooals Plato het reeds inzag, een belemmering zijn, en dus ook ongeschikt om den kerkdienst op te luisteren. Wat de kunst vermag, moet echter niet op gezag van wien ook, maar door degelijke redenen worden uitgemaakt. Ban stelt zich het onderzoek aldus voor: Het eerst moet worden nagegaan, wat men onder toon of stem te verstaan heeft; dan komen de intervallen ter sprake, hunne evenredigheden en verschillen; vervolgens de stappen of sprongen in den zang, en hun onderscheid, dat uit de evenredigheden voortvloeit; daardoor verstaat men alverder de werking van elk hunner op het gehoor en het gemoed. Hierna komt in aanmerking het stelsel, dat de stappen of sprongen te zamen uitmaken; ten slotte de verscheidenheid die bij denzelfden stap of sprong ontstaat door de hoogere of lagere ligging in het toonstelsel, met de werking die men in elk geval te verwachten heeft. Een tweede reeks van onderzoekingen betreft de accoorden van twee of meer stemmen, hunne evenredigheden en uit- 
werkingen op het gehoor en op de gemoedsstemming. Op dit een en ander wordt dan de leer van de toonladders en hare accoorden gebouwd. Het laatste hoofdstuk heeft tot onderwerp de mant en den rhythmus. Wie dit alles bestudeerd heeft kan beginnen te componeren, doch met dien verstande, dat niet enkel het oor hoort, maar de theoretisch ontwikkelde geest het werk voortdurend onder toezigt houdt, en zorgt dat het doel, de muzikale welsprekendheid, niet uit het oog wordt verloren. De ouderen hebben veel aan het licht gebragt, Zarlino, Salinas en andere nieuwere schrijvers zijn nog verder gegaan, zonder echter de theorie te voltooijen; wat verbiedt ons op onze beurt te beproeven, wat er nog verder op goede gronden kan worden uitgemaakt?

Met name valt er aan de regelen van het contrapunt, zooals die tot heden zijn vastgesteld, het een en ander te verbeteren; aan hetgeen hij in dat opzigt ontdekt heeft, moet Ban vasthouden totdat men hem van dwaling overtuigt.

Onmiddelijk na het ontvangen dezer letteren volgde de brief van Huygens aan Boësset (n ${ }^{0}$. XI, p. 10). Hij stelt onzen Ban zeer hoog als theoreticus, zonder hem als componist te prijzen, en verwacht van zijne voorschriften in zake de muzikale welsprekendheid niet het minste gevolg, al houdt hij zich verzekerd dat hij er, in weerwil van alle tegenspraak, met hand en tand aan zal vasthouden. Den laatsten Januarij zond Ban hem nog (XIX, p. CXVIII) een vierstemmige compositie in $\mathrm{G}$ groote terts met de noodige toelichting, waarover hij hem drie dagen later zelf wilde komen spreken.

Hiermede was de strijd tusschen den haarlemschen muziekgeleerde en de Franschen afgeloopen. Op raad van Descartes besloot hij, als voorlooper van zijn groote werk over de beginselen der toonkunst, een proeve op hollandsche woorden in het licht te geven (p. CXIX vv., LV Vv.), en verklaarde kort daarna, den eersten Mei 1642, aan Huygens; (XXI, p. CXX): , Wat er in het vervolg van franschen overlast mogt voorkomen, klopt bij mij aan doovemans deur.... Wordt hij niet redelijk, dan handel ik met zulk een redeloze of doove voortaan niet meer, maar werp de (verwaande) drijvende appelen terug in het water waarin zij behooren." 
De hedendaagsche lezer, die van het weinige dat wij nog van Ban bezitten kennis neemt, zal zich in hoofdzaak met het oordeel van Huygens wel kunnen vereenigen. De man was een echte rationalist, zooals men het noemt, in den geest van zijn tijd, een van die velen wien de wiskundige klaarheid en zekerheid voorzweefde als een in alle kunsten en wetenschappen bereikbaar ideaal. Hoeveel er in een voorwerp dat ons door schoonheid bekoort, onvatbaar blijft voor verstandelijke ontleding, hetzij omdat zijn aard zich daar geheel niet toe leent of (zooals wij $\mathrm{m}$. i. beginnen moeten met te onderstellen) omdat het voor het beschikbare onderscheidingsvermogen al te ingewikkeld is, ontgaat zoo iemand te eenenmale. Op een kunstenaar, die niet gewoon is zich op den weg der wetenschap te bewegen, kan hij daarom niet anders dan een zonderlingen indruk maken. Ziehier wat FranZ. LISZT ons schreef, toen wij hem een prachtexemplaar onzer Hụygens-uitgave hadden aangeboden:

„Le volume, magnifiquement édité, que vous m'arez fait l'honneur de m'envoyer, est tout à fait précieux, et d'un intérêt historique, par son contenu. Nombre de lettres de l'illustre Constantin Huygens sont frappées au coin d'un caractère d'esprit supérieur. Cette correspondance de votre compatriote honore son pays, et sera appréciée en tous pays; particulièrement les musiciens se trouvent flattés d'un tel prédécesseur.

\Comme lecture divertissante, et à la fois sérieusement instructive, je n'en connais pas de meilleure que la dispute entre le sieur Bannins et Monsieur Boesset au sujet de l'air, \$Me veux tu voir mourir." C'est l'ancienne querelle des Gluckistes et Piccinistes, ou mieux in extenso, avec les enjolivements et arguties du pédantisme, la merveilleuse scène $d u$ premier acte $d u$ Misanthrope de Molière. L'Oronte Bannius gagne même un avantage apparent sur son confrère de la comédie: celui-ci se bornait à soutenir que ses vers étaient fort bons, tandis que l'sutre, non seulement soutient l'excellence de son air, mais encore dépèce magistralement l'air de son rival, et fournit les preures que le sien vaut mieux de tous points, depuis la première note jusqu' à la dernière, et > „que tout y est observé par raison." "Etc." (Weimar, 6 Nov. 1882.)

$\mathrm{Nu}$ weten wij echter, dat Ban geen mededinger van den franschen 
componist wilde zijn, maar enkel aantoonen dat diens werk, van hoeveel talent en bedrevenheid het getuigen, en hoezeer het op het gehoor behagen mogt, toch bij gebreke van de juiste opvatting der gestelde taak, een tal van tekortkomingen bevatte, waarmede een goed beredeneerde theorie geen vrede kon hebben. Dat is, zoolang men aan de theorie eenige beteekenis toekent, in beginsel niet af te keuren; is een kunstwerk theoretisch onberispelijk, dan verhoogt dat de waarde die het in andere opzigten bezit; zoo niet, dan late men elk die een uitstekenden aanlcg bezit, zijne verbeelding eenvoudig den teugel vieren, en plage hem niet met theoretisch onderwijs. Evenmin plaatst Ban zich op een leerstoel als onfeilbare wetgever in de muziek, maar hij ontwikkelt de leer waaraan hij de muziekproeven getoetst heeft, en houdt zich dan voor een betere leer, mits met voldoende redenen gestaafd en dus voor ierler die doordenkt verbindend, met aandrang aanbevolen. Alleen om de juiste theorie, en niet om lof voor zijn muziekstukje en zijne persoonlijke begaafdheid is het hem te doen. Hij ontkent niet, dat met theorie alleen, zonder kunstenaarsgave, geen uitmuntend werk tot stand wordt gebragt; het is dus best mogelijk, dat zijn stukje van veel minder waarde is dan die der beide anderen, maar dan ligt dat aan een persoonlijk onvermogen, hetwelk in dit geding niet ter sprake komt. Ban onderneemt iets dergelijks als een Hauptmann of Richter zou doen, die aantoonde dat $b$. $v$. Beethoven in een fuga tegen de strenge regelen had gezondigd, en dan bij wijze van toelichting een onberispelijke fnga op hetzelfde thema leverde, zonder aan de kroon van den meester te willen raken, en ook zonder te beweren dat de aangenomene regelen de best mogelijke zijn, en er bij voortzetting van het theoretisch onderzoek niet nog betere zullen ontdekt worden. Bleek het dan achterna, dat het genie van een Beethoven zich reeds bij voorbaat naar deze betere gedragen had, welnu dan had de theorie de kunst weder ingehaald en had men zich over een vooruitgang te verheugen.

De bedoeling van Ban is inderdaad door de Franschen niet begrepen. Hadden zij hem goed verstaan, dan was het zoo moeilijk riet hem een behoorlijk antwoord te geven.

De geheele quaestie betrof de mate waarin de kunst zich aan 
beredeneerde beginselen te houden heeft. Doorzagen wij hare middelen en werkingen geheel, dan had hij voorzeker gelijk met te meenen, dat wij een gewilde reeks van indrukken op het gehoor en het gemoed zoo naauwkeurig mogelijk dienen te berekenen, even als een ingenieur die een machine ontwerpt om een bepaald werk te verrigten, alles vooruit bedenkt en zoo weinig mogelijk aan een gelukkig toeval overlaat.

$\mathrm{Nu}$ weten wij intusschen van de wijze waarop de uitwerking van een kunstwerk tot stand komt, uiterst weinig, en moeten met onze theorie even voorzigtig blijven als b.v. een geneesheer met het verklaren van verschijnselen en het voorschrijven van leefregels. Met name meent Ban veel te veel te kunnen bepalen omtrent de kracht van elke schrede in de melodie en elk accoord dat door de begeleiding ontstaat. Hij miskent dat die mede afhangt van het voorafgaande en volgende, van de strekking van het geheel, van de stemming, de gewoonten en hebbelijkheden van den toehoorder, van allerhande zamenwerkende omstandigheden, waarvan ons de meeste ontgaan. Zoodat men verstandig doet met een aankomenden kunstenaar op de hoogte te brengen van de meest erkende kunstregelen, hem te oefenen in de gebruikelijke techniek, totdat hij ze als de moedertaal in zijn magt heeft, hem vertrouwd te maken met de beste bestaande kunst, en hem dan verder aan zijn goeden genius over te laten Dit is ons langzamerhand duidelijker geworden, en Huygens besefte het reeds. Ban was, met velen in zijn tijd en daarna, al te doctrinair; trouwens hij was bovenal geleerde, en moet in die hoedanigheid beoordeeld en dan, zoover wij hem kennen, hoog gewaardeerd worden. Het is te betreuren, dat het "Boek van de zinroerende zanghkunst",

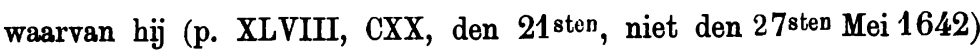
aan Huygens het plan mededeelde, niet gedrukt, en zijne vijf folianten in handschrift niet bewaard zijn gebleven. Wij zouden dan kunnen uitmaken, in hoeverre hij op de beginselen der zeventiendeeuwsche Italianen inderdaad beter dan zijzelven had voortgebouwd.

Leiden, 28 Febr. 1891.

J P N. LAND. 